\title{
Plan estratégico de negocios para la exportación de pequeñas y microempresas
}

\author{
Mg. Econ. Luis DELGADILLO PORTOCARRERO ${ }^{9}$
}

\section{RESUMEN:}

Las pequeñas empresas cumplen un rol fundamental en la generación de empleo, estas constituyen un eslabón determinante en el encadenamiento de la actividad económica y pueden contribuir a incrementar el número de empresas exportadoras, que en el año 2014 fue de 8,032.

En el Perú, las pequeñas y micro empresas son las que más ingresan en el mercado internacional; sin embargo son pocas las que logran permanecer y mantenerse en estos mercados tan exigentes. Esto se debe principalmente a que la mayoría no elabora un plan estratégico de negocios para la exportación, de esta manera se pierden grandes oportunidades de negocio que ofrecen los mercados externos para el crecimiento de sus empresas.

PALABRAS ClAVE: Pequeñas Empresas, Plan de Negocios, Idea de Negocios, Mercados

\section{ABSTRACT:}

Small businesses play a fundamental role in employment generation; these are a crucial link in the chain of economic activity and can contribute to increase the number of exporting companies, which in 2014 were 8,032.

In Peru, small and micro enterprises are most entered into the international market; however there are few who manage to remain and stay in these demanding markets. This is mainly because the majority does not develop a strategic business plan for export, so great business opportunities offered by foreign markets for growing their businesses are lost.

KEY WORDS: Small Business, Business Plan, Business Idea, Market 


\section{DESARROLLO DEL PLAN DE NEGOCIOS PARA LA EXPORTACIÓN}

\section{¿Qué es un Plan de Negocio?}

"El Plan de Negocio es un resumen detallado de la empresa existente, que sirve para ayudar a conocer el negocio, sus antecedentes, los factores de éxito o fracaso, las estrategias y metas".

Una empresa que quiera incursionar en las exportaciones, debe plantearse que la exportación es un objetivo de mediano y largo plazo y como empresario se debe pensar en una estrategia para ingresar a los mercados internacionales y asumir el reto de planificar el trabajo para que sea menos riesgoso y más exitoso.

La forma más sencilla y eficaz es la elaboración de un "plan estratégico de negocios para la exportación", que se convertirá en el documento maestro de tu empresa y en una valiosa herramienta que te permitirá analizar, evaluar y presentar un proyecto de exportación y sobre todo te ayudara a que tu empresa tenga una continuidad de acciones y un crecimiento sostenido en el largo plazo.

EL PLAN DE NEGOCIOS ES UN DOCUMENTO GUÍA DE LA EMPRESA

“Nosotros tenemos que tener metas y objetivos claros, tenemos que tener un objetivo central y justamente nosotros los plasmamos en un plan de negocios, es el documento guía de toda empresa y en el cual nosotros tenemos que tener mucho cuidado primeramente en formularlo y consecuentemente en cumplir sobre todo ejecutarlos como indica el citado documento".

El plan de negocios te permite el seguimiento y autoevaluación de las actividades de tu empresa

Un plan de negocio debe contener lo siguiente:

1. Debes Identificar los objetivos de la empresa para la exportación.

2. Debes especificar las actividades para alcanzar dichos objetivos, para lo cual debes contar con estrategias definidas y claras.

3. Tienes que identificar alternativas de penetración en los mercados internacionales, utilizando diferentes mecanismos y herramientas de promoción comercial.

4. Debes tener en cuenta los medios de transporte, distribución y otras acciones de carácter logístico.

5. Debes tener en cuenta tu capacidad de producción, financiera, de distribución, de diseño

6. Debes tener en cuenta tu rentabilidad proyectada.

7. Debes elaborar un cronograma de las acciones de tu empresa para poder evaluar el cumplimiento de los objetivos y metas trazadas. 


\section{LA IDEA DE NEGOCIO Y SU FACTIBILIDAD}

\section{LA NECESIDAD POR EL PRODUCTO ES UNA OPORTUNIDAD}

En República Dominicana hay la costumbre por ejemplo de usar las motos y motocicletas para llevar pasajeros; entonces si hay la costumbre en el Perú de usar moto taxi acondicionadas para pasajeros entonces puede usarse en ese mercado que es grande y con las mismas características el prototipo usado en Perú. Ellos tienen el mismo problema; si acá funciona porque no puede funcionaren ese país.

Lo primero para un plan es tener una idea de negocio y fijar objetivos que sean claros, alcanzables y realista y rentables. Para tu empresa mediante el análisis FODA podrás analizar los puntos fuertes y débiles de tu empresa y examinar las oportunidades y amenazas del mercado al que apuntas esto te permitirá saber si tu negocio exportador es factible o no; también debes analizar tus VENTAJAS COMPETITIVAS, OPORTUNIDADES COMERCIALES, pautas de CRECIMIENTO y tu COMPETENCIA en el mercado objetivo.

\section{LA OFERTA EXPORTABLE}

La oferta exportable de un país son los productos que pueden ser vendidos en el extranjero, pero la OFERTA EXPORTABLE de una empresa es más que asegurar los volúmenes solicitados por un determinado cliente o contar con productos que satisfacen los requerimientos de distintos mercados.

La OFERTA EXPORTABLE también tiene que ver con la CAPACIDAD ECONÓMICA Y FINANCIERA, CAPACIDADPRODUCTIVA Y CAPACIDAD DE GESTIÓN DE EXPORTACIONES, además debe considerar diferentes variables para analizar tu rentabilidad y tu capacidad de respuesta.

\section{LOS MERCADOS Y SU SEGMENTACIÓN}

Lo primero que uno necesita es conocer para qué público estoy diseñando, si son hombres, si son mujeres, si son jóvenes, si son personas adultas, lo segundo sería lo ideal, viajar y hacer una proyección, miraren la calle lo que la gente utiliza, los colores, su manera de pensar, su idiosincrasia y lo tercero es no perder esa objetividad de convertir esas necesidades en un producto con ventajas competitivas, con estándares internacionales (ISOS) y es más lograr hacer uso de las eco etiquetas.

Para obtener buenos resultados en la exportación, debes localizar mercados atractivos y determinar el potencial de exportación de tus productos, los estudios de mercado te ayudarán a conocer el comportamiento del mercado meta, los factores que tendrás que evaluar son variados. 


\subsection{Tamaño del mercado}

1. Características de la demanda

2. Exigencias de los consumidores

3. Los canales comerciales

4. Diferencias culturales y sociales

¿Que pueden influir en el comportamiento del producto en ese mercado?;

El plan también determinara el segmento del mercado que le interesa a tu empresa; en todo gran mercado hay muchos segmentos distintos entre sí ya que existen diferentes tipos de consumidores según sus ingresos, edades, estilos de vida, oficios o profesiones y niveles de instrucción.

Para poder elegir el segmento del mercado tendrás que contestar las siguientes preguntas:

- ¿Quién va a comprar tus productos en el mercado de exportación?

- ¿Por qué comprarían tus productos?

- ¿Dónde están tus clientes potenciales?

- ¿cuáles son sus características?

Es muy útil prestar atención a las semejanzas y diferencias que existen dentro de los segmentos, para escoger el que mejor se ajuste a tu producto; el segmento del mercado tiene que ser lo bastante grande como para resultar rentable, por ello conviene evaluar su tamaño antes de tomarla la decisión definitiva de incluirlo en el plan de comercialización.

\subsection{Los canales de distribución}

Como exportador debes conocer los canales de distribución que existen para comercializar tus productos por ejemplo:

Puedes elegir la distribución INDIRECTA por una empresa exportadora o crear dentro de tu propia empresa un área de comercio exterior para proyectarte a una EXPORTACION DIRECTA, además puedes vender tus productos por medios de representantes en el extranjero también llamados BROKERS o constituir una filial o un PUNTO DEVENTA PROPIO.

Debes escoger muy bien los canales de distribución y procurar mantener buenas relaciones con todos los interesados la elección dependerá de la estrategia de exportación de tu empresa y del mercado.

Es una necesidad técnica la adaptación de nuestros productos al mercado internacional de nuestro interés; superar las exigencias del mercado es importante porque ello nos va a permitir vender más. Si no nos adaptamos rápidamente vamos a salir del mercado porque hoy en día tenemos que hacer productos que el mercado nos exige y en los cuales este puede confiar de manera sostenida. 
Luego de los estudios y de la segmentación del mercado, debes pensar en adecuar tus productos a los requerimientos del mercado al que apuntas, es decir a los procesos de importación y a su marco legal. Convendrá que analices las posibles modificaciones de los productos para estar de acuerdo a las normas técnicas y certificaciones que exige el mercado de cada país. También debes considerar el cuidado de la presentación los cambios de envase que se requieran, los requisitos de la rotulación y etiquetado la marca y los servicios de posventa. Tus productos deben adaptarse al mercado de destino y si es necesario debes modificarlos para que resulten más atractivos en dichos mercados.

\subsection{Los costos y precios de exportación}

Determinar correctamente los costos y precios de exportación; en un plan de negocios es vital para el éxito de tu empresa. Son muchos los casos de negocios que no prosperan por hacer un cálculo equivocado del precio del producto. Para esto debes considerar los costos de producción que son los que se generan al transformarlos. Los insumos en un bien, incluye en gasto de materia prima, mano de obra y gasto de fabricación, los gastos operativos se generan como parte de proceso de la gestión empresarial que incluyen los gastos administrativos, de venta, de marketing y de personal.

Por último los gastos de exportación como su nombre lo indica se genera en la exportación del producto hasta el momento pactado por el comprador y el vendedor, dependiendo de los términos de contrato se genera costos adicionales como:

- Seguros y fletes internacionales.

- Costos de adaptación de los productos.

- Derechos de importación

- Comisión de los agentes de importación

- Coberturas de los riesgos comerciales y extraordinarios.

También debes considerar los Incoterms, ${ }^{10}$ además tener en cuenta los incentivos que el estado de a las exportaciones no tradicionales como el DRAW BACK, la admisión temporal y la devolución del IGV.

A continuación presento una estructura de exportación, donde se refleja claramente todos los elementos del costo de producción en primer plano y que llegan al nivel \$19138.38; para luego sumarle el margen de 130\% utilidad sobre el costo total de producción de la empresa Nutribar.

Al sumar los cortos totales y la utilidad se obtiene el valor de exportación ex Word( valor en la puerta de la fábrica exportadora), equivalente a $\$ 43937.77$, a los cuales se le sumara todos gastos de exportación que permitan llegar al

10 Los Incoterms son un conjunto de reglas internacionales, regidos por la Cámara de Comercio Internacional, que determinan el alcance de las cláusulas comerciales incluidas en el contrato de compraventa internacional. 
incoterms FOB- Callao( valor de la mercadería sobre el buque), con un valor de $\$ 46247.87$. Estos cálculos son viables cuando el cliente del exterior solicita cotización a valor FOB.

\begin{tabular}{|c|c|c|}
\hline \multicolumn{2}{|l|}{ COSTO TOTAL DE PRODUCCIONN } & $\$ 19,103.38$ \\
\hline $\begin{array}{l}\text { Materia prima (variable) } \\
\text { Envase, empaque, embalaje( var) } \\
6 \text { Obreros (variable) } \\
5 \text { empleados (fijo) } \\
\text { Alquiler, internet (ffijo) } \\
\text { luz,agua ,telef (variable) } \\
\text { Gastos administrativos (fijo) }\end{array}$ & \begin{tabular}{r|}
$11,484.67$ \\
$1,097.07$ \\
$1,678.09$ \\
$4,114.03$ \\
430.00 \\
191.26 \\
108.26
\end{tabular} & \\
\hline UTILIDAD NUTRIBAR (130\%CTP) & & $\$ 24,834.39$ \\
\hline EXW & & $\$ 43,937.77$ \\
\hline TRANSPORTE INTERNO & & \$ 225.00 \\
\hline AGENTE MARITIMO & & \$ 286.70 \\
\hline AGENTE DE ADUANA & & $\$ 1,592.00$ \\
\hline TERMINAL DE LLENOS & & $\$ 206,40$ \\
\hline FOB CALLAO precio de venta & & $\$ 46,247.87$ \\
\hline Precio venta unitario 46,178.87 / 28, & unidades & $\$ 1.6058$ \\
\hline
\end{tabular}

OTRA FORMA DE VER LOS COSTOS DE EXPORTACION ES POR CADA INCOTERMS, POR LO QUE PRESENTAMOS UNA ESTRUCTURA. Dependiendo del Incoterm del que estemos hablando, sumaremos los distintos costes que tiene o prevemos que puede tener nuestro producto desde que "sale" de nuestras instalaciones hasta que se pone a la venta al público en el mercado destino. 
El cálculo ordenado de estos costes nos dará los distintos precios en condiciones Incoterm de que queramos hablar. Es decir, la cadena de precio con los ingredientes que vamos ubicando dentro del cuadro siguiente. Los cálculos presentados están en términos unitarios. Esta estructura de costos nos amplía el criterio en términos de los incoterms, es decir nos permitirá señalar las responsabilidades del exportador y el importador con mayor precisión, hechos que deben establecerse en el contrato de comercio exterior y evitar de esta manera futuros conflictos comerciales.

\begin{tabular}{|l|c|}
\hline Valor FAS(Franco al Costado) & 0,05 \\
\hline Costes de Manipulación & 0,25 \\
\hline Costes Transporte Interno & 0,03 \\
\hline Gastos/Trámites Aduaneros Exportación & 3,95 \\
\hline Total Valor FAS & \\
\hline Valor FOB/FOT/FOR (Franco a bordo Camión/tren) \\
\hline Costes carga Mercancía & 0,01 \\
\hline Costes Tasa Puerto de Salida & 0,16 \\
\hline Total Valor FOB & 4,12 \\
\hline Puerto de Origen: & \\
\hline Valor CIF (Coste,Seguro y Flete) & 0,31 \\
\hline Coste Transporte & \\
\hline Internacional Freight Serra Logistic & 0,03 \\
\hline Coste Seguro & 4,46 \\
\hline Total Precio CIF & \\
\hline Puerto/Lugar de Desembarque & \\
\hline Precio Venta al Importador (DDP) & 0,42 \\
\hline Aranceles y tasas Export mkdb & 0,37 \\
\hline Gastos Portuarios & 7,57 \\
\hline Gastos Transporte en Destino & \\
\hline Total Precio Venta Importador (DDP) & \\
\hline \multicolumn{2}{|l|}{} \\
\hline
\end{tabular}

ADAPTAR NUESTROS PRODUCTOS A LAS EXIGENCIAS DEL MERCADO

Es muy distinto vender en el mercado nacional y en el mercado internacional quizás en el mercado nacional nosotros requerimos cubrir nuestros costos de producción y el margen de utilidad que nos fijamos; en cambio en el mercado internacional hay otros costos aparte del costo de producción, tenemos que determinar los gastos de exportación tenemos que sumar si es que va ir fletes si es que va ir seguro entonces es necesario conocer bien para no cometer errores cuando queramos exportar y no cubrir ni siquiera los costos de producción. 


\subsection{La estrategia de comercialización}

\section{EL CORREO ELECTRÓNICO ES FUNCIONALMENTE PARA LAS EXPORTACIONES}

El 90\% de la comunicación se hace con gente de afuera, el correo electrónico ha pasado a ser la herramienta esencial que toda empresa debe tener; más aún aquella empresa que tiene visión exportadora lo primero que tiene que tiene que hacer es su correo electrónico, es básico y elemental, no hay correo electrónico, no se comunica y pierde oportunidades de negocios internacionales.

La estrategia de comercialización de tus exportaciones deberá considerar materiales de promoción del producto, correo electrónico, perfil de la empresa, catalogo y sitio web de preferencia en inglés. Adecuarse a utilizar medios electrónicos como el Gmail, la página web es vital para una empresa moderna ello te permite contar con una ventana virtual para acercarte al mercado global; asimismo es necesario que salgas a conocer tu mercado meta a través de ferias o visitas de prospección antes de implementarla la estrategia comercial.

\section{INVERTIR EN HERRAMIENTAS DE COMUNICACIÓN Y VISITAS COMERCIALES}

Uno de los mecanismo es la páginas web, los catálogos que pueden ser impresos o en CD, participación en ferias, trasmisiones comerciales, elaborar agendas de negocios.

Viajar, salir al mercado a buscar al cliente y si nosotros enmarcamos la necesidad yo creo que haciendo un pequeño esfuerzo podemos invertir y lograr nuestro objetivo.

\subsection{Los proveedores de servicio de comercio exterior}

Finalmente tener en cuenta que en tu plan de negocio de exportación debes considerar la selección y evaluación de los proveedores de servicio de comercio exterior conlos que trabajarás, estos comprenden:

- Agencias de aduanas, certificadoras

- Agencias de trasporte

- Bancos

- Aseguradoras

- Instituciones de promoción de comercio exterior 


\section{FINALMENTE SE CONCLUYE}

Sin un plan de negocios es como irse a la deriva, llevar un barco sin timón, este aspecto es importantísimo paratoda empresa grande, pequeña o mediana; por lo tanto debe tener un plan estratégico de negocio de exportación que se convertirá en la columna vertebral de tu negocio.

Considerando los objetivos exportadores de tu empresa veras la necesidad de implementar estos instrumentos de gestión estratégicas. El plan de exportación te dará un conocimiento invalorable para generar el éxito de su negocio; llevando a cabo un buen plan de negocios serán cada vez más las empresas peruanas que garanticen su permanencia en el mercado nacional e internacional

\section{RECOMENDACIONES}

6.1. Las pequeñas y microempresas deben apalancarse con la asociatividad para generar una evolución en los mercados internacionales, decisión que le permitirá una sustantiva reducción de costos y gastos de producción, así como, los costos de la distribución física internacional.

6.2. La construcción de un plan estratégico de exportación se torna indispensable y debe contemplar además su interrelación de asociatividad.

6.3. La pequeña y microempresa debe gestionar producir con estándares internacionales, con la finalidad que sus productos logren una confianza cada vez mayor de los mercados internacionales.

6.4. Desde el ángulo del estado es fundamental un aumento de capital en el AGROBANCO con líneas de crédito específico para financiar las exportaciones de la pequeña y microempresa del sector agrícola y agroindustria; además se debe seguir desarrollando nuevas formas de financiamiento con apoyo de la banca de fomento internacional como el BANCO MUNDIAL Y EL BANCO INTERAMERICANO DE DESARROLLO.

\section{WEBGRAFÍA}

1. ADEX: www.adexperu.org.pe/

2. BCR: www.bcrp.gob.pe

3. MEF: www.mef.gob.pe/

4. MINCETUR: www.mincetur.gob.pe/

5. PROMPEX: www.promperu.gob.pe/ 
